\title{
A VIAGEM COMO BUSCA UTÓPICA EM NÃO VERÁS PAÍS NENHUM, DE IGNÁCIO DE LOYOLA BRANDÃO
}

\author{
THE JOURNEY AS AN UTOPIAN SEARCH IN NÃO VERÁS PAÍS \\ NENHUM, BY IGNÁCIO DE LOYOLA BRANDÃO
}

Carla dos Santos Meneses Campos ${ }^{1}$

Ramiro Giroldo ${ }^{2}$

\begin{abstract}
Resumo: A viagem empreendida pelo protagonista do romance Năo verás país nenhum (1981), de Ignácio de Loyola Brandâo, mostra o limiar entre a degradaçăo promovida pelos detentores do poder e o desespero daqueles que buscam a sobrevivência. Trata-se de uma viagem que, ela própria, acaba por se revelar uma difusa procura por uma utopia. Este texto discute a viagem e sua relaçáo com a utopia, assinalando possíveis analogias entre os deslocamentos do protagonista e a "viagem imaginária", compreendida como uma predecessora da "literatura informativa" em voga até o século XIX. Para fundamentar o trabalho, recorreu-se a Causo (2003), com ênfase nas questôes da "viagem imaginária" em relaçấo com a utopia, bem como a Ginway (2005), para explorar as especificidades da distopia brasileira. O interesse é abordar uma peculiaridade do romance: nele, a viagem prenhe de significado e revelaçôes se dá na mesma cidade.
\end{abstract}

Palavras-chave: Horror. Utopia. Distopia. Ignácio de Loyola Brandăo. Năo verás país nenhum.

\begin{abstract}
The journey undertaken by the protagonist of the novel Năo verás país nenhum (1981) by Ignacio de Loyola Brandâo, shows the threshold between the degradation, dominated by those who hold power, and the despair of those who seek survival, thus sustaining the problematic of utopia. In the proposed work, the analysis will take place in the theme of travels and utopia, choosing as a central point the discussion of the similarity between the journey that the protagonist character undertakes and the fantastic travel. For the theoretical basis, the works by Causo (2003) were used, with emphasis on the issues of the fantastic travel in relation to utopia, and by Ginway (2005), about the specificities of the Brazilian dystopian works. Through the readings, it was possible to describe the reason for Souza's trip to occur in the same city.
\end{abstract}

Keywords: Horror. Utopia. Dystopia. Ignácio de Loyola Brandăo. Nâo verás país nenhum.

1 Licenciada em Letras - Português/Inglês (UFMS), realizou Iniciaçāo Científica por dois anos consecutivos com financiamento do CNPq - no primeiro, conduziu uma pesquisa na área de semiótica discursiva; no segundo, sobre a distopia de Ignácio de Loyola Brandâo. E-mail: carlacamposdobrasil@hotmail.com.

2 Doutor em Literatura Brasileira pela Universidade de Sáo Paulo (2012). Atualmente é Professor Adjunto A da Universidade Federal de Mato Grosso do Sul. E-mail: r_giroldo@yahoo.com.br. 
A ficçáo científica se insere em uma tradiçăo que remonta à literatura de viagem. A afirmaçăo pode provocar espanto à primeira vista, mas năo deveria: podem fornecer-lhe o aporte necessário diversos estudos de caráter historiográfico que abordam antecessores da ficçăo científica ou obras primeiras do gênero, como o brasileiro Ficçāo científica, fantasia e horror no Brasil - 1875 a 1950, de Roberto de Sousa Causo - texto ensaístico de fôlego que será abordado adiante neste texto.

Exemplos de literatura de viagem săo bastante conhecidos dos brasileiros: o texto que por vezes é tomado como o marco zero de nossa literatura, a Carta de Pero Vaz de Caminha a el-rei D. Manuel, de Pero Vaz de Caminha, cabe na rubrica. Nas palavras de Alfredo Bosi, a carta é "uma autêntica certidâo de nascimento (...) [que] insere-se em um gênero copiosamente representado durante o século XV em Portugal e Espanha: a literatura de viagens" (BOSI, 2000, pp. 15-16).

Faceta da "literatura informativa", dado o primeiro plano assumido pelo interesse descritivo, a literatura de viagem frutifica no Brasil colonial. À carta, seguem-se outros exemplos: História da Província de Santa Cruz, de Pero de Magalhăes Gândavo; Tratado descritivo do Brasil, de Gabriel Soares de Sousa; Diálogos das grandezas do Brasil, de Ambrósio Fernandes Brandāo; e textos esparsos de Frei Vicente do Salvador e Joâo Antônio Andreoni.

Além dos traços comuns a essa produçâo assinalados por Bosi, como o intuito de atrair novos colonos por meio de uma exagerada valorizaçâo da regiâo, é claro que há características mais genéricas compartilhadas pela literatura informativa europeia como um todo, a saber: o teor descritivo, o tom monológico, o didatismo e a figura textualmente construída de um redator cujas palavras se apresentam como confiáveis.

Lendo Thomas D. Clareson, Causo sinaliza que a obra Utopia, de Thomas More, transforma a literatura de viagem em "viagem imaginária". O lugar a ser descrito, o destino da viagem, o objeto do texto informativo, passa a ser patentemente imaginário, ficcional e dotado de traços fantásticos. Ora, este é um índice essencial, basilar, do que viria a ser chamado de "ficçăo científica". A estrutura da viagem fantástica ou imaginária, segundo Causo, é utilizada para traçar um contraste entre o mundo singular do viajante com o mundo em que o autor da obra vive:

Para que a sátira e a utopia façam sentido, é necessário que o autor pressuponha a existência de falhas no sistema social que ele ataca, e que essas falhas possam ser corrigidas, que o sistema possa ser transformado. Em todo o caso, tais formas antigas de ficçáo científica - dispostas a fazer o leitor alcançar um mundo alternativo onde os problemas da sua sociedade possam ser vistos por uma lente aumentada - dependem de uma sólida consciência de sociedade, estado, governo, classe nacionalidade e do jogo de opiniōes. (CAUSO, 2003, p.59).

Ainda segundo Causo, a "viagem imaginária" é a forma mais antiga ligada à ficçâo científica:

As obras mais antigas apontadas como protoficçăo científica săo viagens fantásticas descritas em épicos antigos: $O$ épico de Gilgamesh, um texto sumério sobrevivente em placas de argila, A odisséia, de Homero, e Argonáutica, de Apolônio de Rodes. (CAUSO, 2003, p. 64). 
Acerca do termo "protoficçăo científica", cabe um breve comentário, posto que aqui se busca uma articulaçâo entre formas narrativas recuadas (a literatura de viagem, a viagem imaginária e, enfim, a utopia) e um romance contemporâneo. Conforme exposto por Causo, é adequado perceber como protoficçăo científica a produçăo que possui marcas comuns à ficçăo científica em épocas anteriores à criaçăo da expressăo. $\mathrm{Na}$ literatura utópica, é importante assinalar, sáo abundantes os exemplos de protoficçăo científica.

O interesse satírico sinalizado por Causo se mantém no romance aqui em pauta, Nâo verás país nenhum, de Ignácio de Loyola Brandăo, ao lado da temática da viagem - bastante transfigurada, é verdade. Este texto investiga a viagem empreendida por Souza, protagonista do romance. Ponto de interesse especular, já que a viagem desvenda tanto o futuro distópico configurado no romance, como também o passado do personagem.

Assinalada a abundância de uma literatura informativa - e de viagem - sobre o Brasil em tempos recuados, cabe estabelecer os rudimentos para uma investigaçấo das relaçóes de afinidade ou de divergência entre tal produçăo e a viagem narrada no romance de Loyola. Colocamo-nos, dessa forma, à frente de uma pouco comum possibilidade de observar, na produçâo literária do Brasil, a abordagem de uma temática própria da ficçăo científica de outrora (a "viagem imaginária") por um romance mais pronta e diretamente vinculado a uma variedade do gênero que floresceu no século $\mathrm{XX}$, a distopia.

Trata-se de uma viagem que, ela própria, acaba por se revelar uma difusa procura pela utopia que serve de contraponto à distopia do entorno. A distopia, variedade negativa da utopia, pode ser dela didaticamente distinguida por meio da formulaçăo de Daniel Derrel Santee:

uma das principais diferenças entre a literatura utópica e a distópica se encontra na impressăo do autor: se ele acredita que está descrevendo uma sociedade melhor, ele está criando utopia. Neste caso, as qualidades distópicas que aparecerem sâo involuntárias; contudo, se ele acredita que está descrevendo uma sociedade repulsiva, o que ele está criando é uma sociedade distópica. Neste caso, ele força as situaçôes e os aspectos a serem repulsivos, entâo eles náo sâo de forma alguma acidentais. Em ambos os casos, a crítica da sociedade é um elemento central. ${ }^{3}$

Como já foi anunciado brevemente, o quadro imaginário do romance Nâo verás país nenhum possui afinidades bastante acentuadas com os textos chamados distópicos - gênero literário cujos paradigmas foram instituídos e fixados por três textos basilares, Admirável Mundo Novo, de Aldous Huxley, 1984, de George Orwell, e Nós, de E. Zamiátin. Uma das características da distopia é o controle de uma entidade soberana sobre os sujeitos, cidadâos controlados em todos os aspectos da vida por uma instância

3 Traduçâo livre de "one of the main differences between utopian and dystopian literature lies in the author's impression: if he himself believes he is describing a better society, he is creating utopia. In this case the dystopian qualities which might appear are involuntary; however, if he believes he is describing a repulsive society, what he is creating is a dystopian society. In this case he forces situations and aspects to be repulsive, so they are by no means accidental. In both cases criticism of society is a central feature" (SANTEE, 1988, acessado em 14/12/2005). 
autoritária. A possibilidade de afirmaçăo das vontades individuais é negada, bem como de qualquer singularidade; tudo deve ser uniformizado: a distopia é radical em sua ojeriza à diferença.

Na obra de Brandāo, o protagonista Souza sofre com a autoridade desmedida de um governo autoritário, com a má distribuiçăo de renda e com um caos no meio ambiente causado pelas próprias autoridades. A obra coloca em cena o limiar entre a degradaçăo promovida pelos detentores do poder e o desespero daqueles que buscam a sobrevivência.

A cidade em que Souza vai empreender sua viagem fantástica tem uma populaçáo que sofre por diversas razóes, entre elas o intenso calor, a falta de água, o desmatamento, a disponibilidade de apenas alimentos industrializados com sabores artificiais, denominados factícios, além de muitos outros problemas que no decorrer do romance vâo sendo revelados. Por onde se anda, vê-se pessoas mortas espalhadas pelas ruas, tornando ainda mais insuportável a vida dos que ali sobrevivem.

A desordem a imperar, assinalemos desde já, năo afasta o romance do gênero distópico, este que é caracterizado pela representaçăo de sociedades excessivamente ordenadas. Isso porque as vontades e a liberdade de escolha dos que habitam o Brasil de Nâo verás país nenhum se veem tăo ordenados quanto na tríade distópica clássica. Há uma ordem imposta, uma ordem que năo tem nenhum interesse de atender às necessidades do cidadâo, antes de controlá-lo em suas menores açôes.

Ainda que assinalada tal imposiçăo, chama a atençăo no quadro imaginário do romance a poluiçâo desmedida que ameaça de maneira catastrófica o meio ambiente - uma representaçấo extrapolada da desordem. É um traço que singulariza o romance em relaçấo às demais distopias, e retornaremos a ele mais adiante.

Souza é um homem de 50 anos, ex-professor de História que trabalhava em uma universidade em Sáo Paulo e mandatoriamente aposentado no início da chamada Grande Locupletaçăo - período em que os ministros foram depostos e um sistema totalitário dominou o País, por meio da propaganda e da violência como veículo de controle das massas. Como ele, muitos outros trabalhadores săo removidos do lugar que escolheram, forçados à aposentadoria pelo novo sistema.

Souza passa a trabalhar como funcionário de uma empresa, aprisionado a uma rotina monótona e desprovida de sentido. Todos os dias, a mesma coisa: "O ônibus chegou. (...) Cruzei a borboleta, năo havia lugares vagos. Normal a essa hora. Cumprimentei pessoas que vejo aqui todos os dias, à mesma hora. (...) Somos parte do S-7.58" (BRANDẢO, 2007, p. 21). A enumeraçáo metódica das açôes, culminando com a identificaçăo com uma massa, parece indicar uma ausência de novidades, uma monótona repetiçâo: amarrado a um percurso definido previamente, Souza se enxerga como parte de um todo indistinto. Diariamente, quando se junta aos trabalhadores que se encaminham ao trabalho no mesmo horário, no mesmo ônibus, ele se integra e se priva de vontades próprias.

Essa rotina se transforma a partir de um misterioso furo que surge espontaneamente em sua măo, elemento insólito que desautomatiza as reaçóes do personagem. Năo há justificativas ou explicaçóes para o furo, como nâo há para a transformaçâo de Gregor Samsa em um monstruoso inseto: o furo é justamente a inexplicável fissura 
no tecido do real, a fissura que acaba por colocar abaixo os parâmetros antes tomados como verdadeiros, aceitos sem nenhuma espécie de questionamento. Quando o real apresenta rachaduras, as estruturas que condicionam a forma com que o mundo é percebido sâo denunciadas.

Contudo, o que se revela a Souza no decorrer do romance é de tăo grandes proporçóes que o caráter insólito do furo se vê obscurecido e perde espaço na narrativa, como se o real a ser desvelado fosse ainda mais insólito, absurdo em sua violência para com o outro. Nâo verás país nenhum parece, nesse ponto, um conto cautelar: seria o caráter fantástico da narrativa corriqueiro se comparado com os nossos próprios arredores, eles sim dotados de contornos autoritários capazes de promover o horror e levar a uma degradaçăo ambiental incontornável?

É a partir do contato com o insólito que o real se desvela. Descoberto o tăo estranho furo na măo, muda de rumo a narrativa do romance, e Souza começa a reagir, a questionar, a se deslocar para além dos caminhos pré-definidos; começa, enfim, a empreender suas viagens extraordinárias na caoticamente labiríntica Sáo Paulo do futuro.

Como o trânsito pela cidade năo é livre, o deslocamento se faz extremamente dificultoso. A viagem de Souza, já a partir desse ponto, é distinta daquela experimentada na literatura de viagem e, depois, na viagem extraordinária. Se os antigos navegadores tinham diante de si o amplo horizonte marítimo e a liberdade de escolher por onde navegar, Souza circula por uma metrópole claustrofóbica que tem o horizonte tomado por prédios e multidōes. Além disso, o Estado autoritário controla seus movimentos, restringe-os. Náo há a emoção da aventura, da descoberta e do desbravamento, mas a claustrofobia, a paranoia e, se as forças policiais conseguem a captura, o horror.

A cidade é dividida em zonas de circulaçâo entre os distritos, cujo acesso é feito por meio de fichas; os cidadâos năo podem usar mais carros, devido ao caos do trânsito. A maioria das pessoas se desloca de bicicleta, mas Souza faz os seus deslocamentos de ônibus. Ele tem passe para o ônibus S-7.58, conseguido graças à corrupçáo na burocracia do Esquema e a uma artrose no joelho:

Quatro para as oito, se năo corro, perco o ônibus. Náo fosse esta perna, eu teria uma bicicleta, como todo mundo. Uma artrose no joelho me impede de pedalar. Tive de passar por dezenas de exames, centenas de gabinetes, paguei gorjetas, conheci todos os pequenos subornos. Escorreguei fichas de água nas măos de funcionários. Fichas que fizeram falta. Transferi cotas de alimentos, e esperei até que saísse a praticamente impossível autorizaçáo para o ônibus. Ganhei a ficha especial de circulaçáo para o S-7.58. (BRANDÂO, 2007, p. 19).

A ficha indica onde ele pode andar, os caminhos que ele pode percorrer, os bairros em que ele tem permissăo para entrar, o lado da calçada onde ele pode seguir. Assim, os seus deslocamentos, como os de todos os cidadâos, sâo controlados pelo Estado: "somos sempre os mesmos dentro do S-7.58. Nos conhecemos todos, mas nâo nos falamos, raramente nos cumprimentamos. Viajamos em silêncio. Sou exceçăo, grito meu bom-dia, os rostos se viram aflitos, perplexos" (BRANDÂO, 2007, p.21). No trecho, chama a atençâo o grito de Souza. É um grito que demonstra uma revolta ou um desejo de mudança, deixando transparecer o seu protesto contra a ordenaçáo excessiva dos menores aspectos da vida - ordenaçâo que desemboca na ausência de movimento, de liberdade. 
Trata-se de um índice tradicionalmente verificável na distopia. Em 1984, os personagens têm também seus deslocamentos vigiados constantemente, mas é o desejo de mudança que confere movimento à narrativa e desperta o horror à vigilância. O protagonista Winston Smith, que trabalha no Ministério da Verdade, Miniver na novafala ${ }^{4}$, também segue todos os dias a mesma rotina monótona:

\begin{abstract}
Winston, com seus trinta e nove anos e sua úlcera varicosa acima do tornozelo direito, subiu devagar, parando para descansar várias vezes durante o trajeto [...] O macacâo azul usado como uniforme do Partido náo fazia mais que enfatizar a magreza de seu corpo frágil, miúdo. (ORWELL, 2009, p. 11-12).
\end{abstract}

E, avesso à rotina, intromete-se o desejo pela mudança: "Se é que há esperança, escreveu Winston, a esperança está nos proletas" (ORWELL, 2009, p.88). Winston acredita e quer que os proletas sejam capazes de algum dia se conscientizar e rebelar contra o poder tirânico. Como no romance de Loyola, a rotina previamente imposta colabora para a despersonalizaçăo, ao passo que sua quebra serve para sinalizar que caminhos outros podem se oferecer. Serve para sinalizar, em suma, que pode (ou deveria haver) a possibilidade de escolha.

O movimento da narrativa é motivado pela esperança que só pode se dar por meio de algum entendimento. Souza vai cunhar, gradativamente, um quadro mais amplo do mundo em que vive, na procura desse entendimento. Lacunar, longe de completamente abarcar as estruturas, mas válido como articulaçăo crítica de teor subversivo. Em outras palavras, ainda que as estruturas năo sejam compreendidas em sua totalidade, a possibilidade de questioná-las se fez presente.

O deslocamento para além do alcance da vigília do Estado distópico é a forma com que Nâo verás país nenhum recupera um elemento da ficçāo científica temporalmente recuada - aquela que tem suas origens na viagem imaginária - ao mesmo tempo em que reconfigura a distopia clássica. Dessa forma, em um único movimento veem-se abordadas sob uma nova visada a viagem imaginária e a distopia tal como o século XX a conheceu.

Em dado momento do romance, Souza, em companhia do amigo Tadeu, se desloca até outro bairro, onde moram os desprezados pelo Esquema: "A maior parte veio de Pernambuco, favelados que viviam nos charcos, se alimentavam de caranguejos" (BRANDÂO, 2007, p.123). É como se esse deslocamento permitisse que o personagem Souza também empreendesse uma viagem em busca do seu autoconhecimento - em específico, a investigaçâo do próprio passado. Dessa forma, a viagem ocorre em dois sentidos: uma no plano físico e a outra no plano interior:

Rastejávamos no meio da estrada, de modo que ninguém nos visse. A free-way projetava-se a quinze metros do solo, dezesseis pistas, larga fita vazia. (...) Bem que o Tadeu recomendou: enfaixa o cotovelo que temos uma longa jornada pela frente, numa posiçâo ingrata. Os primeiros duzentos metros foram difíceis, por causa da artrose, depois entrei no ritmo. (...) Horas e horas sem sair da pista (...) Tento negar, achar desculpas. Sinto falta da Adelaide. Năo sei o que fizemos de nossa vida, por que nos deixamos afastar tanto. (BRANDÁO, 2007,p.121 e 125).

\footnotetext{
4 O uso da palavra "novilíngua" é mais recorrente em outras traduçōes da obra 1984.
}

5 "Proletários", na novafala. 
Nem todos os deslocamentos de Souza, contudo, sâo voluntários: por vezes, o personagem é movimentado à própria revelia. Após ser abandonado pelo sobrinho em um lugar distante, Souza conhece uma jovem, Elisa, e os dois sáo levados para outro lugar pelos civiltares ${ }^{6}$. Essa é uma viagem que Souza é obrigado a fazer, sem ao menos saber o destino. Ao ser levado na viatura com Elisa, Souza começa a delirar. O personagem, nesse ponto, aparentemente perde o contato com os arredores imediatos. Durante o delírio, balbucia desconexo enquanto Elisa tenta trazê-lo à razăo. Em seu delírio, mençóes ao ambiente marítimo onde se deu seu maior trauma recalcado, a morte do filho:

\begin{abstract}
- Estou vendo as sombras no chăo, um mundo de gente sentada. Comem mariscos que as ondas deixam na praia. As ondas náo sâo de água, săo de conchas. Escuta o barulho da água. Onde está você? Me dá a măo, senăo se perde de mim no meio dessa gente toda! Năo te escuto, Elisa. Prenderam minha cabeça, o que văo fazer, me deixem comer mariscos também. (...) Adelaide, olhe as cabeças das criancinhas rolando pela praia, comidas pelos mariscos. Você tinha razăo, Adelaide. Sempre neguei, mas você tinha razăo, as crianças morreram no mar (BRANDÂO, 2007, p. 302).
\end{abstract}

É no horror do delírio do agora, um horror desvelado diante de seus olhos e já impossível de ser escamoteado, que Souza enfim se reencontra com o horror de seu passado. Este, simetricamente, também deixa de ser escamoteado e se desvela. No deslocamento, no contato em primeira măo com facetas antes desconhecidas de sua cidade, Souza também se encontra com o que era desconhecido em seu próprio passado.

A viagem de Souza se dá, no ponto, de maneira singularmente especular: as particularidades dos horrores vigentes na configuraçăo urbana propriamente dita se revelam para ele de maneira sincrônica à descoberta do histórico pessoal. Conhecendo melhor o lugar onde vive, bem como outras pessoas que compartilham da mesma metrópole, seus semelhantes, equivale a conhecer melhor a si próprio. A viagem parece revelar tanto a paisagem externa quanto a interna, levando Souza a um duplo entendimento.

A última viagem de Souza se dá quando decidem transferi-lo para outro lugar, a "Grande Marquise", estrutura que fora criada para proteger a populaçáo dos efeitos devastadores da seca. Em uma extrapolaçăo ficcional do aparato propagandístico movimentado pelo regime militar, com o intuito de criar uma espécie de realidade paralela de tons agradáveis, a Marquise acaba por se revelar um terrível engodo. Trata-se de um grande suporte construído no cáustico deserto, sob o qual centenas e centenas de pessoas sáo despejadas e abandonadas para morrer sem a menor assistência, desprovidas de água, alimentos e cuidados médicos. A Grande Marquise, soluçấo milagrosa oferecida pelo governo, tenderia a resolver o problema do superpovoamento por meio do extermínio em massa.

Durante o percurso, Souza relata: "Desta vez náo vou no carro de presos (...) um vidro me separa do motorista (...). Náo reconheço as ruas, vejo apenas calçadas desertas, batidas de sol." (BRANDÂO, 2007, p. 310). Souza se angustia com aquela situaçăo, năo sabe o que fazer, e continua com suas digressōes: “A perua gira numa viagem infernal, (...) o movimento do carro fará com que penetre algum ar. Ou querem me matar? Perplexo. Por que esse privilégio, ser preso e solto? Na porta de uma igreja batista, o motorista me larga" (BRANDÁO, 2007, p. 311).

6 A milícia cujo nome póe em cena o imbricamento de práticas autoritárias no tecido social. 
Ao ser largado na rua, Souza vagueia por um bairro rico, decide parar em uma parada coletiva de ônibus e percebe que está sendo vigiado por uma câmera: "a câmera de tevê fixada em mim, movo para lá e para cá, ela me segue." (BRANDÂO, 2007, p. 324). Ele escuta uma voz de origem indefinida, que o manda sair daquela parada e continuar o seu caminho: "ANDANDO. CARO CIDADẢO. ANDANDO. ESGOTADO SEU TEMPO. A voz vem de alguma parte neste abrigo, um dos canos deve ser transmissor" (BRANDÁO, 2007, p. 324). Souza náo obedece e passa a divagar sobre sua vida: "Percebo que vivo fazendo perguntas. Logo eu que tinha perdido a curiosidade. Vivia naquele escritório aceitando todos os dogmas, sem jamais indagar, duvidar, rejeitar." (BRANDĀO, 2007, p. 326).

A ausência de liberdade de pensamento e a constante vigilância, traços que costumam aparecer em configuraçóes ficcionais de sociedades distópicas, nâo está presente somente em Nâo verás país nenhum; săo recorrentes no gênero. Em 1984, novamente, a vigilância que tem o interesse de privar os cidadâos da liberdade de pensamento se dá pelas teletelas comandadas pela Polícia das Ideias:

No interior do apartamento, uma voz agradável lia alto uma relaçáo de cifras que de alguma forma dizia respeito à produçâo de ferro-gusa. A voz saía de uma placa oblonga de metal semelhante s um espelho fosco, integrada à superfície da parede da direita. Winston girou um interruptor e a voz diminuiu um pouco, embora as palavras continuassem inteligíveis. $O$ volume do instrumento (chama-se teletela) podia ser regulado, mas năo havia como desligá-lo completamente. (ORWELL, 1984, 2009, p. 12).

Já em Admirável mundo novo, os mecanismos de controle săo aplicados geneticamente e reforçados no decorrer da vida dos sujeitos, fazendo com que os princípios sociais, que sustentam a estrutura do Estado, sejam naturalizados nos indivíduos. Essa situaçăo é retratada na explicaçăo do diretor do centro de incubaçăo e condicionamento aos jovens estudantes de Medicina: "Nós também predestinamos e condicionamos. Decantamos nossos bebês sob a forma de seres vivos socializados, sob a forma de Alfas, ou de Ipsilons" (HUXLEY, 1987, p.11).

E àqueles que năo se sujeitam a esses princípios, como as personagens Bernard Marx e John, o Selvagem, o exílio ou a morte sâo os únicos caminhos possíveis. Segundo Ginway, a "tendência distópica de exagerar aspectos assustadores do futuro permite um delineamento claro do conflito complexo na oposiçáo entre forças do bem e do mal" (GINWAY, 2005, p.138). Para a autora, o romance Não verás país nenhum protesta contra as políticas militares e seu uso da tecnologia: "O foco distópico do romance se evidencia na indicaçăo da culpa pela devastaçăo ecológica à tecnologia importada pelos militares brasileiros". (GINWAY,2005, p.132). Ou seja, a crítica traçada é direcionada a práticas autoritárias, como é tradicional na distopia.

Lembrando-nos que a distopia é pautada pela ordem em excesso, podemos propor que a desordem está em todos os cantos da metrópole do romance nâo por haver menos distopia no romance, mas provavelmente pelos descomunais descaso e incompetência do Estado autoritário nele representado. Descaso e incompetência tăo grandes que o meio ambiente sucumbe a ponto de quase năo mais sustentar a vida - desordem, portanto, que acaba por desembocar em uma ameaça cataclísmica, capaz de exterminar toda a vida no planeta. De acordo com tal lógica interpretativa, autoritários, desinteressados e incompetentes são os militares conforme projetados no futuro de Nâo verás país nenhum. 
Embora Souza já experimentasse os efeitos de tal devastaçăo no seu dia a dia, é a partir dos deslocamentos náo sancionados pela cidade que a extensâo dos danos ao meio ambiente é conhecida pelo personagem, até o ponto culminante sob a Grande Marquise. A viagem parte de uma situaçăo terrivelmente desconfortável, na qual a sobrevivência se faz dificultosa, em direçăo à revelaçáo de que sobreviver naquele país pode ser impossível ou, se ainda houver uma brecha de esperança, quase impossível.

No romance, portanto, Souza principia apegado a uma rotina limitada e a deslocamentos previamente determinados, capazes de revelar apenas uma pequena faceta do contexto distópico. Por meio da condiçâo marginal demarcada pelo insólito furo na máo, o personagem vaga para além dos caminhos previstos e alcança um olhar outro acerca de seu país e de si próprio. O último deslocamento, a última viagem que o romance nos apresenta, é sintetizada por uma citaçăo que, para Ginway, representa "um pequeno vislumbre de esperança ao final do romance" (GINWAY, 2005, p.134). Referese ao astro sobre o qual vagamos, cujo movimento năo vai cessar: "E PUR SI MUOVE - Entretanto move-se [a terra]-Galileu".

Os deslocamentos de Souza no decorrer do romance, voluntários ou năo, apresentam-se como um desvendamento do passado de seu país e de sua história pessoal duas instâncias necessariamente complementares. 0 país que năo se deixa ver, ou que o Estado distópico năo deixa que vejam por inteiro, equivale a um povo que também nâo se conhece. Nâo se conhecendo, é incapaz de articular criticamente a realidade e oferecer a menor resistência.

O deslocamento dá ao viajante a oportunidade de se projetar em uma experiência de descoberta, justamente porque a viagem implica em um distanciamento do próprio contexto e uma espécie de submissăo à influência do ambiente desconhecido. É uma jornada que exige sacrifícios, mas que pode ser trazer benefícios à vida pessoal e à coletiva. Trata-se, também, de um movimento interno: percurso de destinos mais complexos que leva o viajante a dois destinos análogos, o interior e o exterior.

A viagem é, por si só, uma açăo de rebeldia contra a ordem distópica. Ora, a viagem possibilita um olhar mais abrangente do mundo, olhar que pode enfim alcançar as brechas e as deficiências de uma organizaçáo social nociva. Se tal compreensáo de mundo se vê acompanhada por uma compreensăo da história pessoal do viajante, ainda mais significativa se fará a viagem - e ainda mais ameaçadora, consequentemente, ao Estado distópico. Por esse motivo, o deslocamento do cidadáo imerso na distopia precisa ser tăo estritamente controlado: a liberdade de movimento, o proverbial "direito de ir-e-vir", é indissociável da liberdade de pensamento. Livre para viajar (ainda que em uma mesma cidade), livre para pensar: essa é a vontade do cidadăo distópico, é a abertura para o horizonte utópico que a ele cabe. 


\section{REFERÊNCIAS}

BOSI, Alfredo. História concisa da literatura brasileira. 43 ed. Sáo Paulo: Cultrix, 2000.

BRANDĀO, Ignácio de Loyola. Nâo verás país nenhum. Săo Paulo: Global Editora, 1985.

CAUSO, Roberto de Sousa. Ficçâo científica, fantasia e horror no Brasil - 1875 a 1950. Belo Horizonte: Editora UFMG, 2003.

GINWAY, Mary Elizabeth. Ficçâo científica brasileira: mitos culturais e nacionalidade no país do futuro. Traduçăo de Roberto de Sousa Causo. Săo Paulo: Devir, 2005.

HUXLEY, Aldous. Admirável Mundo Novo. Rio de Janeiro: Editora Globo, 1987.

MORE, Thomas. Utopia. Traduçăo de Jefferson Luiz Camargo e Marcelo Brandăo Cipolla. São Paulo: Martins Fontes, 2009.

ORWELL, George. 1984. Traduçăo de Alexandre Hubner e Heloisa Jahn. Sâo Paulo: Companhia das Letras, 2009.

SANTEE, Daniel Derrel. Modern Utopia: a reading of Brave New World, Nineteen EightyFour, and Woman on the Edge of Time in the light of More's Utopia. Florianópolis, 1988. Dissertaçăo (Mestrado em Letras), UFSC. Disponível em: http://www.ead.ufms.br/letras/ daniel/thesis/ Acesso em: 14 dez. 2005.

Submetido em 21 de março de 2018

Aceito em 14 de julho de 2018 